\title{
"SE INSCREVA NO CANAL PARA MAIS VÍDEOS COMO ESSE": CURRÍCULO CULTURAL E SUBJETIVAÇÕES DE GÊNERO NO YOUTUBE
}

Neilton dos Reis ${ }^{1}$

Lana Cláudia Fonseca de Souza ${ }^{2}$

Resumo: O artigo se propõe lançar olhar sobre os currículos que são produzidos a partir de artefatos culturais. Utilizamos como recorte um material audiovisual produzido por jovens de identidade sexuais e de gênero marginalizadas que dizem dessas identidades e marginalizações. Nesse sentido, analisamos os discursos sobre transexualidade que se constroem em um canal do site YouTube, o Canal das Bee. As análises utilizam-se dos estudos culturais e pós-estruturalistas do campo do currículo, que nos possibilitam lidar com os discursos, os artefatos culturais, a educação, os gêneros e as sexualidades como categorias históricas e sociais, constituídas nos jogos de poder e de linguagem. Pensamos o Canal enquanto um currículo que influencia as juventudes e discutimos as verdades construídas acerca da transexualidade e suas (des)subjetivações.

Palavras-chave: Currículo cultural; Gênero; sexualidade; YouTube.

\section{"SE INSCRIBE EN EL CANAL PARA MÁS VÍDEOS COMO ESTE": CURRÍCULO CULTURAL Y SUBJETIVOS DE GÉNERO EN EL YOUTUBE}

Resumen: El artículo tiene como objetivo analizar el currículum que se produce de artefactos culturales. El recorte que utilizamos es un material visual producido por los jóvenes con la identidades sexuales y de géneros marginadas que dicen estas identidades y marginacións. En este sentido, se analizan los discursos de la transexualidad que se construyen en un canal de YouTube, el Canal das Bee. Los análisis se utilizan en los estudios culturales y postestructuralistas del campo curricular, lo que nos permite hacer frente a los discursos, artefactos culturales, educación, géneros y sexualidades como categorías históricas y sociales, formados en los juegos de poder y lenguage. Creo que el Canal es un curriculum que influye en los jóvenes y discuto las verdades construidas sobre la transexualidad y sus (des)subjetividades.

Palabras clave: Curriculum cultural; Género; La sexualidad; YouTube.

\footnotetext{
1 Mestrando em Educação pela Universidade Federal de Juiz de Fora (UFJF) e membro do Grupo de Estudos e Pesquisas em Gênero, Sexualidade, Educação e Diversidade (GESED/UFJF).

2 Doutora em Educação pela Universidade Federal Fluminense (UFF). Professora do Instituto de Educação da Universidade Federal Rural do Rio de Janeiro e coordenara do Grupo de Estudos e Pesquisas em Ensino de Biologia (GEPEnBio/UFRRJ).
} 


\section{Introdução}

Esse texto emerge dos desdobramentos de uma pesquisa que visa à problematização da não-binaridade de gênero ${ }^{3}$ a partir das narrativas de si de pessoas que assim se identificam. Voltamos o olhar, ainda, aos currículos que emergem dessas narrativas sejam eles vindos de espaços escolares, sejam eles artefatos culturais. A partir da ideia de currículo apresentada por Jane Felipe como "um discurso que, ao corporificar as narrativas particulares sobre o indivíduo e a sociedade, nos constitui como sujeitos - e sujeitos também muito particulares" (FELIPE, 1995, p.1), acreditamos ser potente pensá-lo em conexão às subjetividades dos sujeitos. Pensar o currículo a partir das narrativas de si é pensar o que emerge da memória, o que permanece enquanto experiências desses sujeitos.

Pensando com Jorge Larrosa, podemos considerar a categoria experiência como "o que nos passa, o que nos acontece, o que nos toca. Não o que se passa, não o que acontece, ou o que toca" (LARROSA, 2002, p. 22). Disparar na memória currículos que se fizeram experiência é disparar uma série de discursos veiculados a diferentes espaços e tempos da vida. Assim, acreditamos ser impossível hierarquizar as importâncias dos diferentes currículos quando nos debruçamos nas (des)subjetivações - até mesmo no sentido que os currículos se confundem na memória e narrativas dos sujeitos: um currículo com base em um artefato cultural terá reverberações dentro do ambiente escolar, bem como esse último terá reverberações nos modos de apropriação dos artefatos para cada sujeito.

Nesse artigo temos o objetivo de nos debruçarmos sobre os currículos que são produzidos a partir de artefatos culturais. Não pretendemos ter uma ampla visão de todos esses currículos - uma vez que, pela sua multiplicidade, isso seria equivocado e fadado ao insucesso. Pretendemos, entretanto, pensar um recorte bem específico: uma produção realizada por jovens $\mathrm{LGBT}^{4}$ e que fala diretamente às pessoas LGBT (em especial à juventude). Tomamos essa decisão por acreditar na potencialidade em pensar esse nicho: discursos produzidos por um grupo identitário e destinados a ele próprio.

\footnotetext{
${ }^{3}$ Refere-se à identificação de pessoas que não contemplam sua identidade de gênero como $100 \%$ masculina ou $100 \%$ feminina, mas permeiam por elas, fixando-se ou não em identidades entre esses polos ou para além dessa linha.

${ }^{4}$ Elegemos a sigla LGBT para indicar grupos de Lésbicas, Gays, Bissexuais, Travestis e Transexuais. Entendemos que existam muitas combinações desses termos no esforço de representar as diferenças sexuais e de gênero. No entanto, acreditamos que nenhuma combinação dá conta da diversidade de identidades que habitam esses grupos.
} 
Em trabalho anterior (DOS REIS, 2016), pensamos o que Maria Heilborn apresenta acerca do processo de construção de identidade: o modo como o indivíduo se torna um sujeito social, através dos diferentes espaços sociais que ele poderá se inserir ou ser inserido, é influenciador na forma com a qual este enxerga o entorno e a si próprio. Ela afirma que "isto significa dizer, em última instância, que as escolhas e preferências dos indivíduos são socialmente fabricadas" (HEILBORN, 2002, p. 78), de modo que escolhas são feitas tendo por base a moral do meio, a qual delimita certas fronteiras entre sujeitos e/ou grupos sociais.

Ainda em pesquisas anteriores (DOS REIS, 2015), observamos que a identificação com gênero não-binários (e transexualidade/transgeneridade ${ }^{5}$, no geral) se deu também a partir da aproximação e aprofundamento de contato com sujeitos transexuais (e de gênero não-binários) e seus discursos. Muitas identificações surgiram por comparação de histórias de vida: a socialização se torna peça-chave para um melhor entendimento da própria identidade de gênero e enquadramento social, como apontou Anne Fauto-Sterling (2006, p. 40).

Esses resultados nos permitem pensar, entre outras coisas, que jovens LGBT, através da veiculação de narrativas em artefatos culturais voltados à própria comunidade LGBT, podem fazer parte dos processos de construção das identidades de sujeitos sociais. Em outras palavras, os discursos promulgados por esses currículos atravessarão os indivíduos, produzirão verdades, construirão subjetividades.

A partir da pesquisa, escolhemos pensar um currículo em específico bastante evocado nas narrativas de si: um canal no YouTube ${ }^{6}$ que diz da juventude LGBT, o Canal das Bee. O canal é composto por diversos vídeos e seções, com diferentes temas abordados. Para ir ao encontro dos objetivos da pesquisa escolho pensar a temática da transexualidade, sendo possível o levantamento de questões como: quais discursos são veiculados à transexualidade no Canal das Bee? Como se produz esse currículo e quais seus desdobramentos e reverberações na construção de identidades e diferenças? Quais as

\footnotetext{
${ }^{5}$ Transexualidade e transgeneridade são termos tido como sinônimos utilizados para indicar uma identidade de uma pessoa que foi designada a um gênero ao nascer, mas que atualmente se identifica com outro.

${ }^{6}$ YouTube é site de utilização pública na WEB 2.0. A plataforma permite a publicação de vídeos e a interação dos usuários por meio deles. Permite, ainda, a criação de canais: contas pessoais ou empresariais onde se publicam vídeos, geralmente, de temáticas parecidas. É possível acessar o referido canal no endereço eletrônico: https://www.youtube.com/CanalDasBee
} 
verdades construídas acerca da transexualidade? Quais as relações de poder-saber imbricadas no Canal?

Escolhemos rever esses questionamentos a partir de um referencial teórico pósestruturalista. Para Vera Helena Siqueira, “uma das questões centrais dos discursos pósmodernos é sua ênfase na centralidade da linguagem e da subjetividade como novas frentes a partir das quais se repensam as questões de significado, identidade e política" (SIQUEIRA, 2004, p. 5). Assim, olhar para a transexualidade em uma produção de jovens LGBT nesse referencial é se direcionar às potencialidades dessa linguagem nas subjetividades, bem como implicações políticas de identidade e de diferença. Como indica Guacira Lopes Louro,

[...] ao contrário daqueles/as que associam as perspectivas pós-modernas ao abandono das causas coletivas, ao incitamento ao relativismo e à fragmentação, desmobilizadores e apolíticos, acredito que podemos ler, nessas perspectivas, um movimento oposto: o revigoramento e ampliação do político. (LOURO, 1997, p. 123).

Após essa breve introdução, o artigo está dividido em quatro partes: a primeira se propõe pensar teoricamente os contornos de um currículo de artefatos culturais, bem como minha defesa em compreender o Canal das Bee dentro desses contornos; a segunda traz os discursos do Canal que conversam com as temáticas de transexualidade e, ainda, as formas de acesso e seleção metodológica desses discursos; após, pensamos outros atravessamentos e reverberações do Canal enquanto currículo e possíveis olhares que poderiam ser interessantes para o campo do currículo que se pretende pensante dentro dos artefatos culturais; finalizamos com algumas considerações.

\section{Currículos culturais}

O que aqui temos denominado enquanto currículo produzido a partir de artefatos culturais - em consonância com Ruth Sabat (2001): currículo cultural -, é o conjunto de discursos que constroem conhecimentos e saberes e são produzidos por esses artefatos (a exemplificar: artes, mídias, culturas populares, a própria Ciência Moderna etc). Um artefato cultural, para Nilda Alves, é tanto um aparelho quanto uma ideologia e "está sempre encarnado em cada 'praticante' através das diversas redes cotidianas em que o mesmo está enredado" (ALVES, 2003, p. 72). Os currículos produzidos, enquanto construtores de saberes, podem também ser entendidos como disparadores de experiência e subjetivações. 
Acreditamos ser caro pensar a terminologia empregada nesse texto, de currículos culturais. Seria uma falha não sinalizar a redundância que reside em nomear os currículos que aqui são de interesse enquanto currículos culturais, uma vez que é prerrogativa de currículo ser atravessado, determinado e composto/compor as culturas. Todos os currículos são culturais: desde aqueles que o sujeito vivencia nas escolas através dos livros didáticos àqueles que ele experiencia no cinema. Diferenciamos aqui nominalmente, entretanto, para sinalizar currículo cultural como aquele produzido em artefatos midiáticos e artísticos. Apontamos, dessa forma, um canal do YouTube como um currículo cultural por ser produzido em um artefato cultural, não por negar o caráter cultural do currículo escolar.

Conforme o pensamento foucaultiano, é importante lembrar que, enquanto currículo, os artefatos culturais não agem meramente como algo que faz uma representação de determinado conteúdo, mas que atua concomitante a múltiplos discursos formando as verdades e sentidos sobre os quais fala. O currículo cultural será também dispositivo que estabelece um saber, um conhecimento, um nome, uma classificação, uma fronteira e um lugar para sentidos - e sujeitos - que representa.

Pensando com Deleuze e Guattarri (1995), acreditamos que esses currículos podem ser lidos com caráter rizomático, pela sua multiplicidade: não é necessariamente direcionado, mas sim uma trama que não se finda, conectada às outras e onde sempre há espaço, brechas, linhas de fuga e (des)territórios para que ela se expanda.

Tal como o currículo escolar, o currículo cultural envolve um conhecimento organizado em torno de relações de poder, de regulação e controle. Não se trata de afirmar que existe um lugar onde tal organização é detalhadamente planejada, mesmo porque tal lugar não existe. (SABAT, 2001, p. 19)

No mesmo sentido os currículos são organizados e selecionados de maneira fragmentada. Tomemos como exemplo um filme de grande circulação: a seleção ocorre em momentos variados - desde a produção do filme enquanto obra de arte, passando pela sua exibição e circulação, até a escolha de um indivíduo em assisti-lo (em qual momento assisti-lo, com quem, em que lugar etc). Os currículos culturais são assim também descentrados e pouco propensos ao controle. A autora considera, entretanto, imprescindível voltar o olhar a esses currículos culturais, principalmente por pensar que eles são também constituintes de identidades culturais - o que Jane Felipe (1995, p. 1), em consonância, confirma dizendo de currículos enquanto produtores de sujeitos.

Pensando, em específico, nas questões de gênero e sexualidade, Marcio Caetano vai apontar que são variadas as instituições que constituirão as identidades e diferenças: 
família, escola, medicina, Ciência, religião, mídias e artefatos culturais. Todos esses dispositivos irão discursar, quase que hegemonicamente, para uma construção binária do gênero: masculino/feminino - acompanhado de um reforço à constituição biológica macho/fêmea e da heteronormatividade ${ }^{7}$. Assim, "essa dinâmica obscurece outras possibilidades de estruturação das identidades e práticas sexuais" (CAETANO, 2009, p. 9).

No caso desse estudo, interessa-nos especificamente os processos de construção de identidades e significação associados aos discursos produzidos por mídias digitais. Muitas pesquisas têm refletido sobre as mídias digitais na formação dessas identidades (binárias). Para esses estudos (SCORALICK, 2009; FERREIRA e CAMARGO, 2001; PEREIRA, 2008; QUEIROZ, 2005), a mídia é um dos fatores mais marcantes do milênio e é apontada como forte responsável pela formação de (pre)conceitos. Sobre sexualidades marginalizadas, por exemplo, Jandira Queiroz afirma que a mídia brasileira:

[...] é uma importante fonte de informação sobre o mundo para muitas pessoas, imagens equivocadas ou pouco realistas das minorias sexuais têm um efeito nocivo, já que promovem uma ilusão de que estas pessoas não experienciam alegrias, problemas cotidianos ou emoções humanas. Muitas vezes os jovens brasileiros (e adultos também) se espelham em personagens de novelas e a partir disso orientam suas ações. Neste sentido, podemos dizer que as telenovelas são uma ferramenta importante na afirmação de identidades heterossexuais. (QUEIROZ, 2005, p. 51).

Indo ao encontro desse pensamento, diversos estudos (RALEIRAS, 2009; FISHER, 2002; SIQUEIRA, 2004; FELIPE, 1995; SABAT, 2001) têm permeado a pesquisa acerca desses currículos. Todas essas autoras e autores defendem seus objetos de estudo (propagandas, filmes, textos jornalísticos, novelas, músicas etc) enquanto locais de trocas simbólicas e materiais, disparadores de efeitos de verdade sobre gênero e sexualidade. É perceptível nesses textos que nos objetos analisados:

[...] há uma pedagogia, um determinado tipo de currículo que opera através de uma lista de procedimentos e técnicas voltados para produzir e reproduzir tipos específicos de comportamentos, valores, hábitos, atitudes pessoais diretamente conectados com o tipo de sociedade na qual estão inseridos. É, sem dúvida, uma forma de regulação social que tem funcionado no sentido de manter tipos de espaços de segregação de gênero e de sexualidade. (SABAT, 2001, p. 20-21)

Os procedimentos e técnicas que são operados nesses currículos são tanto discursivos, como operacionais. Em análises fílmicas, por exemplo, é possível pensar tanto nas ideias veiculadas através de diálogos, quanto nas ideias imagéticas (jogos de câmeras, sonoplastia, caracterização de personagens etc). No mesmo sentido, em um canal de

\footnotetext{
${ }^{7}$ Diz-se da matriz, conjunto de normas e regras, social e culturalmente construídas que institucionalizam a heterossexualidade como padrão normal para a sexualidade humana.
} 
YouTube muitas coisas dizem para além dos discursos falados: a quantidade de vídeos que são produzidos acerca de determinada temática, em quais momentos sociais-históricosculturais esses vídeos são divulgados, quem são as pessoas convidadas a dialogar com o canal, o cenário e tempo de duração dos vídeos, a quantidade de acessos de cada vídeo, entre outras coisas. Tudo isso é de interesse estudos culturais no campo do currículo, pois tudo compõe as formas de regulação social. É interessante pensar que todo currículo opera, em alguma medida, enquanto regulação. Ainda que se proponha à desconstrução de determinado regime (como o da heteronormatividade, por exemplo), se pressupor constituições identitárias, estará estabelecendo fronteiras e regulações: submetidas a outros regimes de verdade.

Ainda são poucas as pesquisas que se debruçam sobre o caráter curricular (em especial no que tange $\mathrm{s}$ temáticas de gênero e sexualidade) do YouTube. O site apresenta características de facilidade para hospedagem e divulgação de vídeos, de comunicação entre os usuários (através de comentários) e de integração a outras redes digitais. Marco Polo Silva e Shirlei Salesa (2016) o pensam como "ícone da cultura colaborativa na web" e como forte agente na constituição de uma juventude ciborgue - termo empregado para dizer que a "presença dos/as jovens no ciberespaço produz novas maneiras de vivenciar a identidade juvenil e de produzir uma cultura própria do ciberespaço, a cibercultura" (SILVA e SALESA, 2016, p. 6). Para esse autor e essa autora, a juventude se apropria dos vídeos do YouTube (tanto como produtora, quanto avaliadora e consumidora) e os insere nos processos educacionais - sejam eles escolares ou não. Entretanto, sinalizam ainda que "nem todos/as irão se apropriar da mesma maneira deste processo de aprendizagem ciborgue" (SILVA e SALESA, 2016, p. 9). Essas diferentes formas de apropriação irão também dar multiplicidade: o mesmo canal no YouTube - ou ainda o mesmo vídeo - será múltiplo, a depender do sujeito.

Henry Jenkins faz uso da expressão culturaparticipativa para explorar alguns aspectos do site. Para ele, a expressão diz do rompimento com os tipos anteriores de meios de comunicação, onde os espectadores se encontram em passividade.

Em vez de falar sobre produtores e consumidores de mídia como ocupantes de papéis separados, podemos agora considerá-los como participantes interagindo de acordo com um novo conjunto de regras, que nenhum de nós entende por completo. Nem todos os participantes são criados iguais. Corporações - e mesmo indivíduos dentro das corporações de mídia - ainda exercem maior poder do que qualquer consumidor individual, ou mesmo conjunto de consumidores. E alguns 
consumidores têm mais habilidades para participar dessa cultura emergente [participativa] do que outros (JENKINS, 2009, p.30).

Nesse sentido o YouTube ocupa certo papel desestabilizador na produção de conhecimento e saberes: o binário produtor/consumidor é rompido e as relações de poder, ainda que permaneçam, possuem um caráter menos marcado. Pensamos no rizoma de Deleuze e Guattari novamente, uma vez que não admite os binários e busca, exatamente, essa desestabilização.

A partir disso, consideramos potente analisar os vídeos de um canal no YouTube já por essa característica não-binária de relação e identidade das pessoas que participam do mesmo. Mais potente ainda é analisar isso conciliado a um canal que promove o debate das questões de gênero e sexualidade, desestabilizando também os regimes de heteronormatividade. Assim, alguns canais poderiam ser selecionados para que o interesse e os objetivos desse trabalho fossem alcançados (a exemplificar: Põe na Roda, Chá dos 5, Drag-se, Vlogay, Fmastrandea, Coletivo Lumika ${ }^{8}$ ). Escolhemos, no entanto, o Canal das Bee por um conjunto de fatores, entre eles: ser o primeiro canal que trata dessas temáticas no YouTube que nós mesmos acessamos, ter um número significativo de inscritos $(322.324)^{9}$, conter vídeos específicos sobre transexualidade, ter sido citado por alguns sujeitos da pesquisa durante suas narrativas.

O Canal das Bee se inscreveu no site YouTube em 20 de agosto de 2012 e tem, atualmente, 28.188 .957 visualizações. Seus 398 vídeos são classificados em seções (como Bee Fun, Closes das Bee, Bee Viaja, Bee Comenta, Bee Cozinha e Pergunte às Bee). Tais seções têm características específicas: Bee Cozinha, por exemplo, traz vídeos de alguma pessoa que constrói o canal ensinando alguma receita culinária; vídeos do Bee Comenta são lançados em casos específicos que as pessoas do canal julgam importante comentar e colocar posicionamentos; Pergunte às Bee é a seção menos formatada, traz temáticas diversas e, por vezes, pessoas convidadas.

\footnotetext{
${ }^{8}$ Links para acesso:

Põe na Roda: https://www.youtube.com/user/canalpoenaroda

Chá dos 5: https://www.youtube.com/user/chados5

Drag-se: https://www.youtube.com/user/dragsetv

Vlogay: https://www.youtube.com/user/VlogayOficial

Fmastrandea: https://www.youtube.com/user/fmastrandeacanal

Coletivo Lumika: https://www.youtube.com/user/coletivolumika

(Acessos em: 20 de abril de 2017)

${ }^{9}$ Dados numéricos atualizados em 20 de abril de 2017. Desde que esse texto começou a ser escrito (no mês de dezembro do ano de 2016) o canal teve um aumento de mais 20 mil inscritos.
} 
O canal surgiu da necessidade de produção de um trabalho de conclusão de um curso de Comunicação e Multimeios da Pontifícia Universidade Católica de São Paulo. O trabalho, desenvolvido por Jéssica Tauane (atualmente participante do Canal), foi orientado por Pollyana Ferrari e teve como objetivo produzir algo em formato audiovisual para a WEB 2.0 que fomentasse a discussão e o combate ao preconceito ligado às questões de gênero e sexualidade. Jéssica Tauane narra, entretanto, que a criação do Canal não foi apenas uma necessidade acadêmica, mas uma reverberação de sua história pessoal. Nesse sentido, ocorre o que aponta Guacira Lopes Louro: a "objetividade e neutralidade, distanciamento e isenção, que haviam se constituído, convencionalmente, em condições indispensáveis para o fazer acadêmico, eram problematizados, subvertidos, transgredidos" (LOURO, 1997, p. 19). O Canal das Bee enquanto necessidade de produção acadêmica não é dissociado do Canal das Bee enquanto necessidade de promulgação do combate à discriminação que afeta também a criadora.

Para um texto que pretende pensar as reverberações de um canal de YouTube enquanto subjetividades, é interessante perceber que a própria criação desse canal é resultado de subjetivações emergidas de outro canal. O caráter rizomático se potencializa: os princípios de conexão e de multiplicidade elucidados por Deleuze e Guattarri (1995, p. 14) se materializam. Dois canais enquanto currículos se conectam e um pode ser compreendido também como multiplicidade do outro: pontos de um mesmo rizoma. Jéssica Tauane explica como se dá essa ligação em uma entrevista a Bibiana Guaraldi:

\footnotetext{
Entrei no YouTube e havia um canal chamado Dedilhadas, feito por duas lésbicas. Eu, com todo aquele grilo, vi duas meninas lidando naturalmente com o motivo dos meus grilos, daí comecei a pesquisar, a ler e assistir a coisas sobre o assunto e fiquei com esperança. Eu as via e me perguntava: 'será que algum dia vou conseguir ser tão feliz assim?' (GUARALDI e TAUANE, 2016, grifos meus).
}

Foi no encontro com o canal Dedilhadas - um dos canais pioneiros que discutia questões de lesbianidade - que se deu a subjetivação. O Dedilhadas contribuiu para o processo de (re)(des)construção de uma identidade sexual lésbica. A partir desse canal se iniciaram as pesquisas, as leituras e o contato com outros currículos que continuaram os processos de formação dessa identidade - e, ainda, para um novo pensar de uma identidade profissional: enquanto criadora e produtora de audiovisuais para a web.

Ela relata que foi em 2012 que pensou: "gente, acho que eu consigo fazer isso, conversar com esse pessoal que tá passando pelo que passei" (GUARALDI e TAUANE, 2016). A partir de então, o Canal das Bee foi criado: conectado à ideia do que significou o 
Dedilhadas, multiplicizado desse canal. É um mesmo rizoma que se divide numa ruptura a-significante, feito de linhas de segmentaridade.

A descrição no site YouTube do Canal das Bee informa:

Não só um canal contra a homofobia. Um canal contra o preconceito, contra a transfobia, a bifobia, a lesbofobia, o machismo. Um canal a favor da diversão, do riso e de viver a vida do jeito que você quiser. E principalmente, sendo quem você é! Canal das Bee, porque uma abelha só não produz nenhum mel. (CANAL DAS BEE, 2016)

Baseado nessa informação, escolhemos discutir os vídeos a partir de duas dimensões: o caráter identitário que o canal parece promover e a questão da violência contra a população LGBT.

O termo homofobia não contempla as discussões que o veiculo se propõe marcadores identitários são acionados na linguagem para representar outras identidades além da homossexual pressuposta em homofobia. É interessante pensar também que o canal irá eleger fronteiras, através de seus discursos, para essas identidades e que, logo na descrição, percebemos que pensá-las é associá-las, de certa forma, às violências: a marginalização das identidades como algo que as constitui. Se, como Daniel Borillo indica, "a homofobia é um elemento constitutivo da identidade masculina. De fato, ela tem como alvo não somente gays e lésbicas, mas qualquer pessoa que não se enquadre nos papéis determinados pelo sexo biológico" (BORILLO, 2001, p. 35), é provável que ela seja também constituinte de todas as identidades que a circundam: não só a masculina (e heterossexual), mas todas as outras que serão marginalizadas.

Concomitante ao discurso de combate aos atos discriminatórios motivados pela diferença sexual e de gênero, parece haver uma disputa pelas identidades como naturais na própria descrição há a promoção do ser quem você é. O verbo ser parece atuar como um determinante, indicando que para o canal, as pessoas são, não estão sendo. Sinalizo, entretanto, que não considero que as identidades se constituíam em estruturas rígidas e fixas, mas que, com indica Stuart Hall (1997) é uma celebração móvel, continuamente (trans)formada pelos atravessamentos e relações que somos expostos. Dessa forma, as pessoas não são, não há uma fixidez invariável. Retomando Ruth Sabat, percebemos que

As identidades culturais são constituídas a partir das diferentes formas como grupos sociais se reconhecem entre si. Ou seja, as identidades culturais não são dadas apriori, não são preexistentes aos sujeitos, elas se constituem no processo de representação de um grupo, sempre em relação a outros grupos, que carregam características diferentes daquele que está sendo representado. (SABAT, 2001, p. 15) 
Assim, são com essas duas dimensões de análise já anunciadas na descrição do canal que prosseguimos com esse artigo. E é a perspectiva de constituição de identidades a partir das aproximações e distanciamentos, da diferença, que operamos para pensar o Canal das Bee e suas formulações sobre a categoria transexual.

\section{Subjetivações em Identidade e violência}

Dos vídeos publicados pelo Canal até o início da construção desse texto, identificamos (através do título e descrição) cerca de 30 que tratam diretamente as questões de transexualidade, ou seja, vídeos que traziam pessoas transexuais como convidadas (para falar especificamente de transexualidade ou não) ou falavam diretamente sobre a temática. Desses, 21 fazem parte da seção Pergunte às Bee. Escolhemos nos debruçar sobre tais vídeos por alguns fatores: a concentração de vídeos nessa seção, o elevado número de pessoas convidadas e o caráter planejado (ou, ao menos, mais planejado que a seção Bee Comenta - na qual os vídeos são produzidos para suprir uma demanda específica de algo que ocorreu no cenário LGBT brasileiro e/ou internacional). A seleção para esse texto ocorre, assim, através do nome do vídeo e da sua descrição, procurando por palavras-chave como: transexualidade (ou apenas trans), não-binaridade, diversidade de gêneros, transgêneros.

Todos os vídeos foram assistidos, somando cerca de 3 horas e 20 minutos. Dos 21 vídeos, 20 tiveram a presença de pessoas convidadas (todas transexuais ou travestis), como: Laerte, João W. Nery, Ariel Silva, Daniela Andrade e Maria Clara Araújo. Para a organização desse artigo iremos transcrever algumas falas dos vídeos, identificando como Participante (para pessoas que constroem o Canal) e com o próprio nome quando a pessoa for uma convidada. Os vídeos serão nomeados aqui de acordo com sua data de publicação: sendo Video 1 o mais antigo e o Vídeo 21 o mais recente.

A primeira temática que sinalizamos para pensar a formação construída no Canal das Bee acerca das realidades transexuais é o próprio entendimento de identidade de gênero (e, também, orientação sexual). Em vários vídeos essas definições são retomadas por diferentes pessoas convidadas, entretanto o discurso de descolamento das dimensões gênero (identidade) e sexualidade (orientação sexual) permanece em todos eles. Isso indica para certo posicionamento alinhado aos estudos de gênero e sexualidade, em especial aos de Judith Butler, (2003, p. 38). A autora, mesmo não colocando essas dimensões enquanto totalmente separadas, vai apontar que esse descolamento só é percebido quando se 
apresenta em diferença à norma (no caso, ela diz de gêneros “ininteligíveis") e, para as pessoas que se identificam dentro da norma não há separação - o que cria as linhas de inteligibilidade, ou seja, barreiras que impedem a compreensão do gênero e sexualidade como dimensões não obrigatoriamente imbricadas. Entretanto, esse discurso é apenas parcialmente alinhado, uma vez que o Canal das Bee vai criar as fronteiras de identidade e de orientação sexual como:

Luiza: Assim, Identidade de Gênero o que é? Como eu me identifico, eu comigo mesma, como você se entende. É uma coisa mais individual. [...] Orientação sexual é pra quem eu desejo direcionar. É uma relação com o outro. E isso foi sempre muito confuso pra mim.

(VIDEO 14)

Participante: Uma coisa que esse vídeo vai servir é pra isso: explicar pra galera que identidade de gênero é uma coisa, sexualidade é outra completamente diferente.

(VIDEO 2)

A partir disso sinalizamos, agora, para um distanciamento da ideia de Judith Butler, que vai entender todos esses dispositivos dentro de uma mesma matriz: a heteronormativade. Para além, Scott vai expandir a noção de constituição da identidade de gênero:

O gênero implica quatro elementos: os símbolos culturalmente disponíveis que evocam representações simbólicas (...), os conceitos normativos que põem em evidências as interpretações do sentido dos símbolos (...), uma noção de política bem como uma referência às instituições e organização social (...) e a identidade subjetiva (SCOTT, 1990, p. 14-15).

Assim, a análise sugere que, na disputa de sentidos acerca da transexualidade e identidade de gênero, a dimensão subjetiva é aquela que ganha território no currículo do Canal, o que pode implicar em posicionamentos e aprendizagens (pra quem assiste ao veículo) limitadas no que tange às dimensões política e simbólica, por exemplo. A própria noção de identidade (não apenas de gênero) é dimensionada nesse campo e colocada em oposição ao rótulo (ou estereótipo), sem a problematização da ideia de que as identidades são construídas também em face das fixações de sentidos que os estereótipos instituem: algo que não é estabelecido pela natureza (aqui sem questionar o próprio entendimento de natureza), mas que terá fortes marcadores sociais, históricos e culturais.

Participante: Rótulo é uma imagem pré-definida de alguém (...). E você nunca vai conseguir fazer isso com um grupo de pessoas. Porque ai que vem a identidade. Identidade é o que te torna você. É você mesmo. Único.

(VIDEO 19) 
Quando considera a identidade como o que te torna você, o Canal parece não operar com a ideia que ele próprio influencia nas identidades enquanto veículo constituidor de sujeitos. A ideia de identidade enquanto natureza é reforçada no Vídeo 01, principalmente quando traz elementos biológicos no discurso. Nesse sentido, as discussões que eram travadas no campo do gênero e da sexualidade acerca do rompimento com o binário natureza/cultura - proposto, por exemplo, por Anne Fausto-Sterling (2006, p. 17) - são retomadas com outra perspectiva: naturalizar as identidades de gênero. Em outras palavras, o currículo que o Canal das Bee parece propor nos vídeos analisados, em linhas gerais, não é o de questionar a natureza de qualquer identidade (seja ela cissexual, ou transexual), mas o de "legitimar" as identidades transexuais através de um discurso que as coloque no patamar de biológica, natural.

Como temos operado ao longo desse artigo pensando a identidade com Stuart Hall (1997) como algo móvel, discordamos de tal posicionamento. Não discordamos que as identidades transexuais devam ser legitimadas e que, então, possam estar asseguradas enquanto direito. Indo ao encontro de Deborah Britzman, acreditamos que uma identidade, ainda que heterossexual ou cissexual, por exemplo, não seja "automática, autêntica, facilmente assumida; nenhuma identidade sexual existe sem negociação ou construção" (BRITZMAN, 1996, p. 74). Assim, a própria defesa desses vídeos do Canal das Bee das identidades de gênero como um extrato natural é uma construção, uma subjetivação para os sujeitos que encontram o Canal como currículo cultural. Resta, então, questionar: quais outras construções o Canal realiza acerca transexualidade? Que outras verdades são construídas? Por quais outras subjetivações as pessoas podem passar ao assistir aos vídeos? Quais as fronteiras que limitam a identidade transexual do Canal das Bee? Em um dos vídeos, a pessoa convidada traz uma construção bem delimitada de uma identidade transexual: a travesti.

Maria: A identidade travesti é uma identidade latino-americana. Ela surge a partir de um contexto proletário, ela surge de um contexto de exploração, de pessoas exploradas. E essas meninas acabem vendo a prostituição como única maneira de se viver, porque elas perderam os pilares que colocamos como os mais importantes pra viver: família, escola e trabalho. Elas não têm mais essa base infelizmente, a maioria de nós. É como se fosse um destino dado para a maioria de nós.

(VIDEO 18)

A identidade travesti é mais que associada à exploração e violências, ela é colocada como emergente desse contexto: a prostituição e a violação dos sentidos tradicionais dos 
pilares (família, escola, trabalho) como marcadores. Prosseguimos então com a segunda dimensão para pensar a transexualidade nesses vídeos: a violência. Em todos os vídeos assistidos ela apareceu com parte das histórias das pessoas convidadas pelo Canal e, mesmo no único vídeo que não havia narrativas de si, ela fez parte do discurso. A construção realizada pelo canal indica que ser transexual e travesti é ter uma identidade que será, em diversos momentos, constituída em meio à violência.

Observamos que o Canal escolhe operar com essas identidades a partir das histórias de violência - mesmo nas narrativas de pessoas convidadas que não foram expulsas do contexto familiar ou que não passaram por situações violentas na escola ou no emprego, sempre é suscitada a questão da violência que atinge a maioria das pessoas. Assim, pensamos que uma pessoa que se forma pelo Canal das Bee, que é atravessado por esses vídeos, será subjetivada a pensar essas identidades enquanto existências violentadas.

\begin{abstract}
Daniela: No Brasil existe uma expectativa de vida de trinta anos para travestis e transexuais, o resto da população brasileira existe a expectativa de vida de 78 anos de idade. Pra mim é arrasador saber uma coisa dessas, mas infelizmente isso não comove ninguém. Eu moro num país em que 90\% das mulheres trans e travestis se prostituem. Não existe qualquer paradigma dentro da sociedade de um grupo populacional que 90\% dessa população esteja se prostituindo. Mas isso não comove ninguém.
\end{abstract}

(VIDEO 8)

Quando Daniela diz ser arrasador saber uma coisa dessas, a categoria experiência é, novamente, acionada na análise: experiência como "algo que (nos) acontece e que às vezes treme, ou vibra, algo que nos faz pensar, algo que nos faz sofrer ou gozar" (LARROSA, 2014, p. 10). O sofrimento ao saber as estatísticas - e estar em permanente estado de vulnerabilidade a essa realidade - se faz experiência como algo que a subjetiva, como algo que faz sofrer, que é arrasador. No mesmo sentido, para alguém que assiste aos vídeos e tem uma identidade próxima a do discurso de Daniela (compartilha sentidos com o discurso produzido por Daniela), isso se poderá se constituir como um disparador da experiência: que também poderá se manifestar enquanto sofrimento. As estatísticas dizem das vulnerabilidades, são devir-violências.

Daniel Borrillo opera com o conceito de homofobia (aqui expandida para transfobia) social para dizer que, em alguns casos, se "pretende simplesmente perpetuar a diferença homo/hetero, pregando a tolerância, uma clemência policiada dos ortodoxos para com os hereges" e, nesse sentido, "não choca ninguém o fato de eles não gozarem dos mesmos 
direitos que os heterossexuais" (BORRILLO, 2001, p. 20). Identificamos o conceito quando Daniela insiste que isso não comove ninguém.

Em alguns momentos dos vídeos, essas experiências de violência são mais latentes e saltam às histórias de vida. O discurso de identidade transexual enquanto natural já discutido é retomado para dizer das realidades de violência:

Maria: Existe um ciclo de vida natural na vida de uma mulher trans, de uma
travesti. Ela se assume, ela sai da escola por causa do preconceito, ela é
colocada pra fora de casa, ela para na prostituição porque não tem emprego e
quase sempre essa menina morre. (VIDEO 10)

Participante: O que implica ser um homem trans negro?

Leo: Implica das opressões que a gente passa. O homem trans negro já é invisivel por ser trans, por ser um homem trans. Então a questão da negritude ela perpassa de uma maneira bem específica e clara, porque a primeira coisa uma pessoa identifica na outra é a cor da pele.

(VIDEO 13)

Os dois trechos indicam o que Daniel Borrilo diz acerca da homofobia/transfobia: “ela está tão enraizada [...] que, para se desfazer dela, um verdadeiro exercício de desconstrução de nossas categorias cognitivas se impõe" (BORRILLO, 2001, p. 34). Pensamos que esse enraizamento se dá tanto em quem comete agressões transfóbicas, quanto em quem as sofre. Se, para Maria, o ciclo de vida das travestis é marcado pelo preconceito, pela prostituição e pela morte, e para Leo a interseção das duas identidades transexual e negro - se dá pelas opressões que sofre, as violências estão subjetivadas, experienciadas para pensar identidade. Por conseguinte, enquanto currículo cultural, o saber produzido pelo canal também poderá ser assim enraizado.

\section{Outros atravessamentos curriculares}

Observamos que o Canal das Bee, enquanto artefato cultural e currículo, tem potencialmente um caráter rizomático. Isso fica presente em todos os vídeos assistidos para a construção desse texto de duas formas. A primeira, e mais evidente, aparece quando em cada vídeo outros currículos culturais são acionados: links são disponibilizados, livros e filmes são indicados, referências de outras mídias digitais são acessadas. Entre os currículos culturais citados pelo Canal, é possível destacar o curta-metragem $O$ amor que não ousa dizer seu nome; os livros Eu trans, a alça da bolsa - relatos de um transexual, Viagem solitária e Meu nome é Amanda; os sites Transempregos, Capitolina e Blogueiras negras; e outros veículos, como dados acadêmicos de transfobia de Jaqueline Gomes de 
Jesus (pesquisadora da Universidade de Brasília), História em Quadrinhos divulgada sobre a história de uma professora transexual e a Conferencia Internacional do SSEX BBOX. Em um dos vídeos, os próprios participantes do Canal sinalizam:

Participante: a gente usa muito os textos que a Daniela publica no facebook. A gente aprende, a gente se informa através deles e usa eles pra passar informação pra vocês.

(VIDEO 6)

A segunda maneira que o Canal faz ressaltar a multiplicidade do rizoma é através das próprias narrativas que traz nos vídeos. Histórias das pessoas convidadas pelo canal se entrecruzam, como os diferentes pontos do rizoma. Jô Lessa, participante do Vídeo 12, narra, por exemplo, como foi seu encontro com João W. Nery, participante dos vídeos 3, 4 e 5 .

Jô: Quando ele [João W. Nery] começou a palestra dele, que ele foi contando a vida dele. Aquilo foi, sabe? Eu tava vendo a minha vida ser contada pela boca de outra pessoa. [...] Eu renasci naquele momento. Eu me reconheci naquele momento. Eu pensei: caraca eu não tô sozinho. [...] Agora eu encontrei uma pessoa igual a mim, depois disso eu conheci outras iguais a mim, agora tem um grupo grande.

(VIDEO 12)

O discurso de João W. Nery pode ter provocado subjetivação em Jô Lessa, no mesmo sentido o de Jô Lessa pode subjetivar outros tantos. O rizoma não tem limites para a multiplicidade e pode ser acessado em qualquer ponto. Um currículo cultural rizomático se estabelece e conecta os vídeos, as histórias de vida, os discursos e os outros currículos culturais que o Canal movimenta.

Indo ao encontro do trecho acima, é ser interessante ressaltar que, apesar do Canal trazer o discurso de naturalização das identidades, ele também traz relatos de "descoberta" dessas identidades. Assim, é o conceito de acontecimento ${ }^{10}$ é trazido para as narrativas, mas na perspectiva de identidades que são reveladas, não construídas.

Erik: Primeiramente ocorreu uma falta de informação mesmo. Não existe visibilidade trans. Nem sabia que existia trans e pensava "ah sou lésbica”. Mas não me enquadro nisso. Eu não gosto de pensar como mulher. Ai depois que eu descobri esse universo trans através do Facebook que eu me achei. É isso que sou.

(VIDEO 2)

Ariel: Comecei flertando com travestilidade, porque como eu não via como era uma representação material do que é não-binária, eu comecei a flertar com

\footnotetext{
${ }^{10}$ Em perspectiva foucaultiana, podemos entender acontecimento como uma ruptura com uma verdade ou uma singularidade, provocando dessubjetivação no lugar e no momento de sua produção.
} 
travestilidade achando que era algo que me representava. E ai depois que eu tive ciência do binário de gênero que eu percebi que não era bem por aí.

(VIDEO 9)

Laerte: O clube do Crossdress foi onde eu comecei. Agora eu não fiquei lá porque a dinâmica das ideias e das propostas foi muito pra fora-pra fora, quer dizer, para um outro campo. A ponto de eu achar que não tinha mais sentido a chamada identidade crossdress, que bem ou mal se caracteriza por essa vivência intermitente da representação feminina.

(VIDEO 15)

Todos os relatos convergem para os já sinalizados estudos de Maria Heilborn (2002): as construções da transexualidade, travestilidade e/ou não-binaridade ocorrem através de um processo que perpassa por outras identidades. A identidade atual (entendida por alguns sujeitos como o final do processo, a identidade que foi descoberta ou revelada) é uma construção resultada das "escolhas, baseadas na ordem de valores do grupo social no qual ele [o sujeito] foi criado e vive" (HEILBORN, 2002, p. 78).

A falta de informação apontada por Erik, o flerte com a travestilidade e depois o tomar ciência do binário de gênero de Ariel e o não permanecer em função da dinâmica das ideias e das propostas terem escapado de Laerte são exemplos desse movimento - bem como uma sinalização da importância dos currículos culturais para esse processo. E o Canal se reconhece dentro dessa importância.

Participante: Tem muita gente que assiste o canal que não tem contato com, por exemplo, gênero não-binários, que não sabem o que é etc. Então a gente trazendo essa pauta, muita gente pode se identificar.

(VIDEO 9)

Laerte: O canal das Bee é importantíssimo. Pra que crianças como essas [lgbt] tenham um apoio e entendam que há modelos positivos, há gente legal.

(VIDEO 16)

No sentido oposto, os currículos culturais podem criar outras realidades para a transexualidade - e, a depender da amplitude do discurso desses outros currículos, subjetivar muito mais pessoas. É o que aponta Daniela, uma das convidadas a falar no Canal.

Daniela: eu falo sempre que a mídia vai lembrar da transexual por cinco motivos, sempre vão ser só esses motivos: pra criminalizar, somos todas criminosas; pra patologizar, somos todas doentes mentais; pra exotificar, "olha o homem que virou mulher! O homem que quer se mulher! Olha, o homem que tá enganando as pessoas"; ridicularizar, "porque olha, é motivo de riso né! O traveco, a sapatão que quer ser homem”; e pra hipersexualizar, porque a mulher trans e a travesti ela "tá querendo sexo a todo tempo". 
A análise de Daniela parece ir ao encontro da análise desse artigo, no sentido de pensar a mídia - ou artefatos culturais, no geral - como construtora de discurso, um veículo que disputa sentidos, acerca da transexualidade. A convidada parece não considerar as mídias não-hegemônicas (como próprio Canal das Bee) enquanto agentes nessa disputa. Entretanto, nos parece interessante sinalizar que análises como essa de cunho curricular são feitas no âmbito do próprio Canal.

\section{Considerações Finais}

Outras temáticas poderiam ser exploradas nesse texto, como as modificações corporais, as experiências familiares, a prostituição e as questões empregatícias. Entretanto, alguns discursos se mostraram divergentes nos vídeos, até mesmo entre as participantes do Canal. A prostituição, por exemplo, é tratada como violência em alguns vídeos, mas também como liberdade em outros. Isso se dá, principalmente, em função do canal selecionar diversas pessoas, com discursos concorrentes por vezes, como convidadas - o que salienta algumas características curriculares: a seleção e a disputa.

Cabe destacar, ainda, que existe uma forte ideia de representatividade presente no currículo cultural do Canal das Bee. 20 vídeos, dos 21 assistidos, contêm pessoas convidadas e todas são transexuais ou travestis. Na perspectiva de Tomaz Tadeu da Silva (2000, p. 97), entendemos que representatividade "refere-se às formas textuais e visuais através das quais se descrevem os diferentes grupos culturais e suas características". Nilma Crusoé investiga essa questão de representatividade aliada ao currículo escolar, acredito, apesar disso, que seja aplicável aos currículos culturais: a representação "permite ao sujeito interpretar o mundo, facilita a comunicação, orienta as ações e comportamentos" (CRUSOÉ, 2004, p. 113). Assim, essa orientação de ações e comportamentos estará sendo promovida pelos discursos dos vídeos, enquanto os sujeitos se sentirem representados por aquelas pessoas convidadas.

Para finalizar, diante do que foi discutido, acreditamos ser potente investigar o Canal das Bee como um currículo cultural produzido por membros da comunidade LGBT e direcionado à própria comunidade. Esse direcionamento diz diretamente sobre o que o Canal entende e constrói para suas próprias vivências de sexualidade e identidades. Escolher se debruçar sobre as questões de violência, por exemplo, é escolher fomentar um currículo que traz questionamentos e orientações de rompimento com algumas realidades contemporâneas. No mesmo sentido, os vídeos analisados apostam hegemonicamente em 
um descolamento entre a identidade de gênero e sexualidade, na ideia de essencialismo em detrimento da noção de construção - pensamos que seja uma operação em desencontro à complexidade da formação das identidades e experienciação das sexualidades.

Analisamos o Canal das Bee como promotor de um currículo potencialmente rizomático e que pode suscitar outros olhares e outras discussões. Esse texto nos movimenta novos questionamentos: como operam os artefatos culturais conectados ao Canal das Bee? Que outros currículos culturais participam dos processos de construção identitárias das juventudes LGBT? Existe uma forma de produção caracterizada pelo encontro dessas duas identidades de juventude e $L G B T$ ? Como as pessoas interagem no Canal - quais são os comentários, as discussões e as reverberações? De que maneiras o Canal tem reverberações para além da dimensão virtual da vida de suas participantes? Todas essas novas questões poderão se constituir em novas formas de se debruçar sobre o Canal das Bee e outros currículos culturais.

\section{REFERÊNCIAS}

ALVES, Nilda. Cultura e cotidiano escolar. Red. Revista Brasileira de Educação, 2003. BORRILLO, Daniel. Homofobi $a$. Barcelona: Bellaterra, 2001.

BRITZMAN. Deborah. O que é esta coisa chamada amor: identidade homossexual, educação e currículo. Revista Educação e realidade, São Paulo, v. 21, n.1. p. 71-96, jan/jun.1996

BUTLER, Judith. Problemas de gênero: feminismo e subversão da identidade. 236p. Rio de Janeiro: Editora Record, 2003.

CAETANO, Marcio. Currículos praticados e a construção da heteronormatividade. 32 $^{\mathbf{a}}$ reunião da ANPED. Caxambu/MG, 2009.

CANAL DAS BEE. Disponível em: <http://www.youtube.com/canaldasbee> . Acesso em: 14 de dezembro de 2016.

CRUSOÉ, Nilma. A teoria das representações sociais em Moscovici e sua importância para a pesquisa em educação. APRENDER - Caderno de Filosofia e Psicologia da Educação. Vitória da Conquista Ano II n. 2 p. 105-114 2004. 
DELEUZE, Gilles; GUATTARI, Fêlix. Mil platôs-capitalismo e esquizofrenia, vol. 1/Tradução de Aurélio Guerra Neto e Célia Pinto Costa. Rio de janeiro: Ed, v. 34, p. 94, 1995.

DOS REIS, Neilton. Diversidade de gêneros e Ensino de Biologia: casos de prazeres e corporeidade não-binários. Monografia. 105p. 2015.

DOS REIS, Neilton. Movimentação estudantil: identidades sexuais e de gênero em trânsito. Revista Mosaico. Rio de Janeito. v. 7, n. 11. 2016.

FAUSTO-STERLING, Anne. Cuerpos sexuados: la política de género y la construcción de la sexualidad. Barcelona: Melusina. 526p. 2006.

FELIPE, Jane. Gênero e sexualidade nas pedagogias culturais: implicações para a educação infantil. Silva, p. 195, 1995.

FISCHER, Rosa Maria Bueno. O dispositivo pedagógico da mídia: modos de educar na. Educação e pesquisa, v. 28, n. 1, p. 151-162, 2002.

GUARALDI, Bibiana e TAUANE, Jéssica. "Sou muito mais que lésbica”, diz youtuber do Canal das Bee. Folha de São Paulo. 2016. Disponível em:

$<$ http://www1.folha.uol.com.br/tec/2016/09/1815891-sou-muito-mais-do-que-lesbica-dizyoutuber-do-canal-das-bee.shtml> Acesso em: 14 de dezembro de 2016.

HALL, Stuart. Identidades culturais na pós-modernidade. Trad. Tomaz Tadeu da Silva, Guacira Lopes Louro. Rio de Janeiro: DP\&A, 1997.

HEILBORN, Maria. Fronteiras simbólicas: gênero, corpo e sexualidade. Cadernos Cepia. Rio de Janeiro. v. 5, p. 73-92, 2002.

JENKINS, Henry. Cultura da convergência. Tradução Susana Alexandria. 2. ed. São Paulo: Aleph, 2009.

LARROSA, Jorge. Algunas notas sobre laexperiencia y sus lenguajes. Trajetórias e perspectivas da formação de educadores. São Paulo: Editora UNESP, p. 19-34, 2002.

LARROSA, Jorge. Tremores: escritos sobre experiência. Trad.: Cristina Antunes e João Wanderley Geraldi. Belo Horizonte: Autêntica, 2014.

LOURO, Guacira Lopes. Gênero, sexualidade e educação. Petrópolis: Vozes, 1997. 
QUEIROZ, Jandira. Rumo ao final do arco-iris: O que mudou no discurso sobre personagens homossexuais na grande midia de entretenimento na ultima decada e por que? 66p. 2005. Trabalho de Conclusão de Curso. Centro Universitário de Brasília.

SABAT, Ruth. Pedagogia cultural, gênero e sexualidade. Estudos Feministas. Santa Catarina. n. 09. 2001.

RALEIRAS, Mónica Sofia da Costa et al. Identidade, internet e subjectivação: os sites de redes sociais. Dissertação. Universidade de Lisboa. 2009.

SCOTT, Joan. Gênero: uma categoria útil para os estudos históricos. Educação e Realidade, v. 16, n. 2, p. 5-22, 1990.

SILVA, Tomaz Tadeu (org). Identidade e diferença: a perspectiva dos estudos culturais. Petrópolis: Vozes, 2000, 133p.

SILVA, Marco Polo Oliveira; SALESA, Shirlei Rezende. O fenômeno cultural do youtube no percurso educacional da juventude ciborgue. Disponível:

$<$ http://s3.amazonaws.com/academia.edu.documents/38614659/Artigo_SBECE_Marco_Po lo.pdf?AWSAccessKeyId=AKIAJ56TQJRTWSMTNPEA\&Expires=1482733204\&Signat ure $=$ gtb5nqwqDX5\%2BBphBzMn4AL7gAZA\%3D\&response-contentdisposition $=$ inline $\% 3 \mathrm{~B} \% 20$ filename $\% 3 \mathrm{DO} \_$fenomeno_cultural_do_Youtube_no_percur.p df> Acesso em 14 de dezembro de 2016.

SIQUEIRA, Vera. Sexualidade e gênero: mediações do cinema na construção de identidades. Anais da 27 ${ }^{\mathrm{a}}$ ANPED Sociedade democrática e educação: qual universidade, p. 01-19, 2004.

YOUTUBE. Disponível em: <http://www.youtube.com>. Acesso em: 14 de dezembro de 2016. 